\title{
A INFLUÊNCIA DO DIREITO PRIVADO PARA A CONSOLIDAÇÃO DAS CLÁUSULAS GERAIS PROCESSUAIS NO PROCESSO CIVIL BRASILEIRO
}

\author{
Clarice Santos da Silva ${ }^{1}$ \\ Rosalina Moitta Pinto da Costa ${ }^{2}$
}

\begin{abstract}
RESUMO
Esse artigo propõe-se a demonstrar a influência exercida pelo direito privado para a inserção das cláusulas gerais processuais como técnica legislativa amplamente utilizada na ordem jurídica processual civil brasileira vigente. Parte-se do desenvolvimento dos contornos valorativos do direito privado, como fruto da transformação da metodologia jurídica do século XX, buscando descrever como essa mudança de paradigma impactou a ciência processual civil e a sua construção normativa. Utiliza-se de pesquisa teórica, qualitativa, eminentemente bibliográfica, com o emprego do método hipotético dedutivo.
\end{abstract}

Palavras-chave: Cláusulas Gerais Processuais; Metodologia Jurídica; Direito Processual Civil; Direito Privado; Código de Processo Civil.

\section{THE INFLUENCE OF PRIVATE LAW FOR THE CONSOLIDATION OF PROCEDURAL GENERAL CLAUSES IN THE BRAZILIAN CIVIL PROCESS}

\begin{abstract}
This article proposes to demonstrate the influence exercised by private law for the insertion of the general procedural clauses as a legislative technique widely used in the Brazilian civil procedural legal order in force. It begins with the development of the evaluative aspects of private law, as a result of the transformation of the legal methodology of the twentieth century, trying to describe how this paradigm shift impacted civil procedural science and its normative construction. Theoretical, qualitative, eminently bibliographical research is used, using the hypothetical deductive method.
\end{abstract}

Keywords: General Procedural Clauses; Legal Methodology; Private Right; Civil Procedural Law; Civil Procedure Code.

\section{INTRODUÇÃO}

1 Doutoranda e Mestre pelo Programa de Pós-Graduação em Direito da Universidade Federal do Pará (PPGD/UFPA), com ênfase em Direito Processual Civil. Graduada em Direito como Discente Laureada pela Universidade da Amazônia (UNAMA). Assessora Jurídica do Ministério Público Federal no Pará (MPF/PA). Orientadora do Núcleo de Estudos Avançados em Direito Processual Civil da Liga Acadêmica Jurídica do Pará (NEADPC/LAJUPA). Fundadora e Conselheira da LAJUPA. Professora de Direito Processual Civil da Graduação do Centro Universitário FIBRA. E-mail: ssantosclarice@gmail.com.

${ }^{2}$ Doutora em Direito das Relações Sociais (PUC/SP). Mestre em Direito Agrário (UFPA). Especialista em Direito Ambiental (UFPA). Especialista em Direito Civil e Processo Civil (ESMPA). Professora de Direito Processual Civil da Universidade Federal do Pará (UFPA). Professora Permanente do Programa de Pós-Graduação Stricto Sensu em Direito da Universidade Federal do Pará (PPGD-UFPA). Coordenadora do Grupo de Pesquisa "Inovações no Processo Civil” (UFPA/CNPQ). E-mail: rosalina.costa@ hotmail.com. 
O presente artigo se destina a analisar a relevância das contribuições do direito privado para a instituição da técnica legislativa das cláusulas gerais processuais como um dos pilares de organização normativa da ordem jurídica processual civil brasileira, demonstrando como a alteração da metodologia jurídica do século XX, identificada com proeminência no campo do direito civil, impactou o modo de compreensão dos demais ramos da ciência jurídica, inclusive o processual. Para cumprir esse propósito, o trabalho é desenvolvido a partir do exame analítico de três pontos.

O primeiro deles está centrado na narrativa da construção do modelo de direito privado brasileiro, com a preocupação de verificar a alteração do perfil valorativo do direito civil ao longo do tempo, migrando paulatinamente de um modelo de legalidade estrita até se alcançar uma maior abertura interpretativa. Vale observar que essa análise é realizada sem pretensão de esgotar a exposição dos antecedentes históricos que envolvem a temática, servindo, ao revés, à finalidade de fornecer um contexto temporal adequado para subsidiar o estudo desenvolvido nas seções seguintes.

No segundo momento de análise, há a descrição das cláusulas gerais, sua definição, origem e incidência no direito civil, destacando a sua ampla utilização normativa no ordenamento jurídico nacional, a exemplo da inserção das consagradas cláusulas gerais da boafé, e da função social do contrato e da propriedade.

Por fim, o trabalho é encerrado com a demonstração da importância das cláusulas gerais processuais para o processo civil brasileiro, notadamente a partir da vigência do Código de Processo Civil de 2015, responsável por consolidar o emprego dessa técnica legislativa no campo processual, sendo este fenômeno, de um lado, relevante reflexo da alteração metodológica realizada no campo do direito privado e, de outro, um mecanismo de fortalecimento da efetividade da justiça civil brasileira.

\section{A RECONSTRUÇÃO DO MODELO DE DIREITO PRIVADO BRASILEIRO}

Há inequívoca contribuição das reformulações das bases do direito privado para a instituição da técnica legislativa das cláusulas gerais como um dos pilares de organização normativa da ordem jurídica processual civil brasileira. A alteração da metodologia jurídica do século XX, identificada com proeminência no campo do direito civil, impactou o modo de compreensão dos demais ramos jurídicos, inclusive o processual. 
Não se olvida que a compreensão contemporânea que se tem do direito privado é fruto de gradual e profundo desenvolvimento histórico, cujo percurso foi trilhado não apenas pelo direito civil - ramo por excelência do direito privado $^{3}$ - como por toda ciência jurídica; afinal, como já ressaltado, o direito é fenômeno acentuadamente histórico.

O estudo das sociedades dos séculos XIX e XX revela a existência do modelo liberal de organização do direito e traz à tona a predominância do dogma da codificação, o qual se pauta na ideia de unidade e completude jurídica, identificando no Estado o centro da produção normativa e na racionalidade o seu pilar de estruturação (RAMOS, 1998, p. 03).

Segundo destaca Carmem Lucia Silveira Ramos, o fenômeno do liberalismo jurídico se consagrou em resposta ao regime absolutista e seus privilégios de classe, “eliminando, ao mesmo tempo, o que foi qualificado como o caráter dispersivo e inseguro do direito do medievo, pelas peculiaridades de sua conotação pluralista" (1998, p. 04). Com efeito, a concepção liberal surgiu a partir da promessa de proteção do indivíduo frente aos abusos de poder do Estado, encontrando-se comprometida com o combate aos privilégios estamentais ostentados na época (SARMENTO, 2004, p. 22).

Tratou-se de período em que esteve em voga o Estado de Direito, com primazia, de um lado, à liberdade do cidadão e, de outro, à valorização da segurança e previsibilidade na produção da norma jurídica e no comportamento estatal (MORAES, 2006, p. 65) ${ }^{4}$. Estava-se diante, pois, da era da codificação; do direito legislado por meio de leis que veiculam regras jurídicas compreendidas a partir de uma ótica de suficiência, precisão e completude em seu alcance e sentido (ABBOUD; CARNIO; OLIVEIRA, 2015, p. 297) ${ }^{5}$. Esse período foi marcado pela representação dos códigos como conjunto de normas disciplinadoras de todos os âmbitos da

${ }^{3} \mathrm{O}$ dualismo entre direito público e privado é utilizado no trabalho com fins históricos e didáticos, sem representar a compreensão de separação estanque entre esses dois âmbitos. A ótica de absoluta cisão entre público e privado não mais se sustenta, não sendo sequer compatível com a ordem constitucional vigente, dotada de fluidez e intersecção entre os ramos do direito. Dessa maneira, "em virtude da estruturação do Estado Constitucional e da influência do constitucionalismo, a dicotomia direito público e direito privado sofreu profunda transformação" (ABBOUD; CARNIO; OLIVEIRA, 2015, p. 282).

${ }^{4}$ Aliás, "[...] a exigência de estabilidade, ou de previsibilidade, quanto aos comportamentos individuais passou a ser o pressuposto intrínseco das relações jurídicas, na medida em que a burguesia francesa, vitoriosa da Grande Revolução, se tornara a nova classe dirigente, portadora da tábua de valores na qual toda a sociedade foi chamada a reconhecer-se. O 'mundo da segurança' é, portanto, o 'mundo dos códigos', os quais consubstanciam, em ordenada sequência de artigos, os valores do liberalismo do pacífico século XIX" (MORAES, 2006, p. 65).

5 "Na realidade, o século XIX demanda uma segurança jurídica que o direito natural não havia conseguido proporcionar, daí a importância de o séc. XIX instituir-se sob o império da lei, sem que isso, necessariamente, caracterizasse perda da liberdade" (ABBOUD; CARNIO; OLIVEIRA, 2015, p. 297). 
convivência social (SARMENTO, 2004, p. 30) ${ }^{6}$, identificados enquanto leis que possibilitam a igualdade jurídica entre os indivíduos (RAMOS, 1998, p. 05).

Os códigos civis desse período foram editados com aspiração à unidade e perenidade ${ }^{7}$, como frutos do Estado de Direito, iluminista e racional, segundo Maria Celina Bodin de Moraes pontua (2006, p. 67). Como se sabe, o início desse movimento é associado, tradicionalmente, à instituição da codificação francesa no ano de $1804^{8}$, estando presente também, vale observar, no Código Civil brasileiro de 1916 (RAMOS, 1998, p. 05).

Sob a lógica do paradigma liberal, vivenciada predominantemente até o século $\mathrm{XX}$, a rigorosa separação entre a sociedade e o Estado representava um meio necessário para alcançar a garantia da liberdade individual. $\mathrm{O}$ reconhecimento de direitos fundamentais era destinado à limitação da atuação dos governantes, atuando com fins de contenção de arbítrios e abusos de poder, em benefício da proteção da liberdade dos governados (SARMENTO, 2004, p. 28). Assim, os direitos fundamentais "demarcavam um campo no qual era vedada a interferência estatal, estabelecendo, desta forma, uma rígida fronteira entre o espaço da sociedade civil e o do Estado, entre a esfera privada e a pública, entre o “jardim e a praça”" (SARMENTO, 2004, p. 28). A sociedade e o Estado possuíam campos de atuação bastante distintos e com nítidas demarcações, acreditando-se ser esse - a mínima ação estatal - o caminho para a adequada tutela de direitos.

6 “"...] no catecismo do constitucionalismo liberal, o locus exclusivo de regulamentação das relações privadas era o Código Civil, que, tendo como pilares a propriedade e o contrato, buscava assegurar a segurança e a previsibilidade das regras do jogo para os sujeitos de direito nas relações recíprocas, a partir de uma perspectiva (falsa) de asséptica neutralidade diante dos conflitos distributivos" (SARMENTO, 2004, p. 30).

7 "El Código Civil se erige entonces en la verdadeira carta constitucional de esa sociedad autosuficiente, sancionando los principios de la autonomía de la voluntad y la libertad contractual como ejes de la regulación de las relaciones jurídicas inter privatos" (UBILLOS, 2006, p. 302).

${ }^{8}$ Neste ponto, é preciso fazer um registro. Em que pese classicamente se atribua ao Código Napoleônico de 1804 a inauguração da era codificada, há importantes fatores históricos que antecederam a sua promulgação e que contribuíram para a estruturação desse período, o que representa que, sem desconsiderar a sua relevância histórica, tal diploma continuou um movimento que já se desenhava à época. Do mesmo modo, sinaliza Sebástian Ernesto Tedeschi (2001, p. 161-162): "El proceso codificatorio no tiene su origen en el Código Napoleónico, sino por el contrario, éste constituye la culminación o concretización de un proceso que se venía desarrollando como exigencia de los cambios en el mundo de la vida social, política y económica europeo desde el renacimiento y con el desarrollo creciente del capitalismo". 
Todavia, o aumento da complexidade das relações sociais ${ }^{9}$, assim como a materialização de importantes fatores históricos, como as duas grandes guerras mundiais vivenciadas no desenrolar do século XX, levou a uma profunda modificação na metodologia jurídica e a uma significativa revisão ${ }^{10}$ nos pilares do direito privado, conduzido, a partir disso, pelo questionamento acerca da legitimidade do Estado de Direito e quanto aos riscos do emprego da legalidade estrita ${ }^{11}$.

Assim, rompeu-se com uma concepção unidirecional dos direitos de liberdade no campo do direito privado, passando-se a identificar a existência de uma nova relação entre o Estado e a sociedade, para além de um simples objetivo de contenção de arbitrariedades. Essa transformação impactou a clássica distinção entre as esferas pública e privada, reformulando o papel da Constituição e das codificações (UBILLOS, 2006, p. 306) ${ }^{12}$. Se antes, sob o prisma liberal, as constituições eram destinadas a prescrever a estrutura básica do Estado e a garantir direitos individuais, passaram, agora, a se ocupar de uma multiplicidade temática, "assumindo funções de direção das instâncias políticas e da própria sociedade” (SARMENTO, 2004, p. 40), as quais antes eram destinadas com exclusividade às regulações tipicamente privadas.

9 "Vivemos um tempo de crescente complexidade das fontes do Direito. É fácil depreender que essa complexidade é um epifenômeno da complexidade crescente da vida social" (ASCENSÃO, 2017, p. 403). Além disso, como recorda Edgar Morin (2007, p. 27): "A complexidade dos problemas de nosso tempo nos desarma, torna-se necessário que nos rearmermos intelectualmente, instruindo-nos para pensar a complexidade, para enfrentar os desafios da agonia/nascimento desse interstício entre os dois milênios, e tratar de pensar os problemas da humanidade".

${ }^{10}$ Esse cenário pode ser relacionado com o pensamento de Anthony Giddens (2002, p. 26) ao abordar os atributos da reflexividade da modernidade: "Em relação ao conhecimento científico tanto social quanto natural, a reflexividade da modernidade acaba por confundir as expectativas do pensamento iluminista embora seja produto desse pensamento. Os fundadores originais da ciência e da filosofia modernas acreditavam estar preparando o caminho para o conhecimento seguramente fundamentado dos mundos social e natural: as afirmações da razão deveriam superar os dogmas da tradição, oferecendo uma sensação de certeza em lugar do caráter arbitrário do hábito e do costume. Mas a reflexividade da modernidade de fato solapa a certeza do conhecimento, mesmo nos domínios centrais da ciência natural. A ciência depende não da acumulação indutiva de demonstrações, mas do princípio metodológico da dúvida. Por mais estimada e aparentemente estabelecida que uma determinada doutrina científica seja, ela está aberta à revisão - ou poderá vir a ser inteiramente descartada - à luz de novas idéias ou descobertas".

${ }^{11}$ Nesse sentido, Maria Celina Bodin de Moraes (2006, p. 67): "Se o Estado de Direito, iluminista e racional, se mostrou insuficiente para proteger a coletividade frente ao totalitarismo mais abjeto, tornouse necessário abandonar a legalidade em sentido estrito, permissiva de arbitrariedades e ditaduras, em direção a opções mais seguras, nas quais os princípios da democracia, da liberdade e da solidariedade não possam jamais ser ignorados".

12 "Este enfoque unitario, que tiende a superar el tradicional aislamiento de la Constitución del resto del ordenamiento, tiene una gran transcendencia en la medida en que impide que el Derecho constitucional y el Derecho privado puedan concerbirde como compartimentos estancos, como mundos separados que discurren en paralelo y están gobernados por lógicas radicalmente diferentes" (UBILLOS, 2006, p. 306). 
$\mathrm{Na}$ ordem jurídica brasileira, a Constituição passou a cuidar de questões diversas, plurais e heterogêneas, dentre elas as relações privadas. Como é possível notar, "a Constituição, em suma, não é mais a 'Lei do Estado', mas o Estatuto Fundamental do Estado e da sociedade" (SARMENTO, 2004, p. 40). Houve a demarcação do fenômeno da publicização do direito privado, e, em especial, da constitucionalização do direito civil, sendo este substancialmente permeado pela normativa constitucional, a qual passou a ser seu necessário filtro interpretativo.

Como Maria Celina Bodin de Moraes enfatiza, no campo do direito privado:

o 'mundo da segurança' deu lugar a um mundo de inseguranças e incertezas [...], a ética da autonomia ou da liberdade foi substituída por uma ética da responsabilidade ou da solidariedade [...] e a tutela da liberdade (autonomia) do indivíduo foi substituída pela noção de proteção à dignidade humana (2006, p. 72).

Por essa razão, não é raro encontrar estudos que afirmem estar o direito civil vivendo um estágio de incertezas e indefinições ${ }^{13}$ - até mesmo uma crise de identidade - (MORAES, 2006, p. 60), em razão de ter passado de um modelo liberal-individualista para um socialhumanista (LEAL, 2016, p. 07), o que refletiu em sua abertura e fluidez normativa. Então, o novo direito privado revisita os ideais do direito moderno, assim como o direito processual, consoante se indica em seguida, apresentando caráter de pluralidade e sincretismo na tutela de direitos, não mais estando restrito à esfera particular do sujeito.

Essa transformação histórica não ficou restrita aos limites do direito privado, expandindo-se, assim, para a totalidade da ordem jurídica, sendo responsável pela migração da clássica era da codificação do direito para, primeiramente, a era da descodificação - a partir da elaboração de normas esparsas e especializadas voltadas, sobretudo, à proteção de sujeitos e direitos envolvidos em situações de especial vulnerabilidade ${ }^{14}-$, desaguando na atual era da

${ }^{13}$ Merecem atenção as palavras de Edgar Morin (2010, p. 15) acerca da fluidez do tempo futuro e da complexidade da interação dos diversos fatores sociais: "A evolução não obedece nem às leis nem aos determinismos prepotentes. Não é mecânica nem linear. Nela não existe um fator dominante que permanentemente comanda a evolução. O futuro seria facilmente predizível se a evolução dependesse de um fator predominante e de uma causalidade linear. Precisamos, ao contrário, partir da inépcia de toda predição fundada numa concepção evolutiva tão simplista. A realidade social é multidimensional; ela comporta os fatores geográficos, econômicos, técnicos, políticos, ideológicos... Num dado momento, alguns destes fatores podem ser dominantes, mas existe rotatividade no domínio. A dialética não caminha sobre os pés nem sobre a cabeça; ela gira, pois é antes de tudo jogo de inter-retro-ações, isto é, elo em perpétuo movimento".

${ }_{14}$ Sobre o tema, Claudia Lima Marques e Bruno Miragem (2014, p. 196): "No direito privado, nossa análise concluiu que o pluralismo de fontes tem sua origem no reconhecimento de direitos individuais dos membros destas uniões ou grupos, assim destacam-se do Código Civil as fontes da criança e do adolescente, do idoso, dos portadores de necessidades especiais, dos consumidores, para citar alguns dos 
recodificação, em que a produção normativa volta a se concentrar nos códigos, os quais apresentam, contudo, um novo conteúdo de teor valorativo e finalista, consoante ressalta José de Oliveira Ascensão (2017, p. 407-408).

No Brasil e na Europa, de modo proeminente, verifica-se o retorno da base normativa jurídica para o sistema codificado (COSTA FILHO, 2017, p. 533); a estruturação do direito por meio de codificações, e não mais a concentração na construção sucessiva de microssistemas de proteção, volta a ser a tendência de estruturação normativa.

Nesse âmbito, é relevante compreender que o movimento de recodificação não equivale à reedição dos códigos oitocentistas, cuja linguagem e estrutura partiram de concepção predominantemente legalista, com objetivo de comportar normas completas, precisas e livres de margens interpretativas para seus comandos.

Em verdade, a recodificação representa o reaparelhamento dos códigos por meio da instituição de normas pautadas, em variados níveis, em cláusulas gerais e conceitos jurídicos indeterminados, proporcionando maior abertura ao sistema jurídico, sendo fenômeno contemporâneo distinto daquele vivenciado sob o paradigma liberal de certa clausura cognitiva e semântica.

\section{DEFINIÇÃO E INCIDÊNCIA DE CLÁUSULAS GERAIS NO DIREITO CIVIL E PROCESSUAL CIVIL}

Alberto Gosson Jorge Junior, um dos primeiros autores a escrever sobre as cláusulas gerais no país, afirma que o emprego de uma ótica funcional do Estado auxilia a encontrar o ambiente propício para a inserção de cláusulas gerais para dotar o sistema jurídico de mobilidade suficiente para enfrentar as situações cambiantes (2004, p. 11-12).

Judith Martins-Costa, autora que também desenvolve relevantes estudos sobre o tema das cláusulas gerais na ordem jurídica brasileira, expõe que há a instituição de modelos jurídicos abertos e modelos jurídicos fechados, não sendo essa classificação uma questão de natureza ou essência, e sim de nível ou gradação, sendo o referencial o grau ou a intensidade de determinabilidade da norma $(2015$, p. 75).

Nessa esteira, os modelos jurídicos são considerados fechados quando a estatuição e consequência estão dispostas de modo mais ou menos claro e determinado na estrutura

aqui escolhidos para nossa primeira análise [...] O pluralismo de fontes legislativas é hoje total, a ponto do diálogo das fontes nacionais e internacionais (mesmo soft law) nascer o novo direito privado mais social e solidário". 
normativa (MARTINS-COSTA, 2015, p. 75). De outra banda, está-se diante de modelos jurídicos abertos quando as estruturas normativas apresentam baixo grau de determinação, em sua estatuição, consequência ou em ambos (MARTINS-COSTA, 2015, p. 75). Por certo, o emprego de cláusulas gerais está alocado no segundo grupo.

Há a compreensão de que a cláusula geral é uma técnica legislativa contraposta à casuística (MACÊDO, 2013, p. 02). Essa última consiste em método legislativo de fixação de rígidas hipóteses fáticas, assim como de exata definição dos efeitos jurídicos decorrentes da incidência da norma. Já a primeira é formatada pelo legislador de modo a possuir conteúdo amplo, aberto e flexível ${ }^{15}$, cabendo ao aplicador da norma a identificação do espaço atinente ao suporte fático e à consequência jurídica decorrente de sua aplicação (DIDIER JR., 2010, p. 119).

A técnica da casuística é acompanhada do exercício do método interpretativo da subsunção, por meio da realização do enquadramento exato do fato ao enunciado normativo, de modo rígido e necessário (MÜLLER, 2017, p. 94). A cláusula geral necessita de método diverso da subsunção; desenvolve-se, assim, por concretização, e não por subsunção (DIDIER JR., 2010, p. 120). Isso ocorre em razão das cláusulas gerais serem oriundas da necessidade normativa de propiciar maior abertura ao sistema jurídico ${ }^{16}$, permitindo a oxigenação do direito com base em valores metajurídicos, como ressalta Julio Müller (2017, p. 95).

Nas palavras de Judith Martins-Costa (2018, p. 174):

As cláusulas gerais têm por função auxiliar a abertura e a mobilidade do sistema jurídico, propiciando o seu progresso mesmo se ausente a inovação legislativa. A abertura diz respeito ao ingresso no corpus legislativo de princípios, máximas de conduta, standards e diretivas sociais e econômicas, viabilizando a captação e a inserção de elementos extrajurídicos de modo a promover a adequação valorativa do sistema (abertura ou permeabilidade do sistema). A mobilidade diz respeito à acomodação no interior do sistema desses novos elementos,

\footnotetext{
15 "Por meio delas [cláusulas gerais] se encontrou uma forma de aproximar a lei dos fatos sociais que regulam. A mobilidade, a dinâmica, a rapidez com que se desenvolve a sociedade não pode ser perfeitamente acompanhada pelos códigos e as cláusulas gerais permitem sua adequação às particularidades do caso concreto. Trata-se de uma nova forma de pensar sistematicamente, integrada a todo o ordenamento jurídico" (RACY, 2011, p. 03).

${ }^{16}$ É importante perceber que ao lado das cláusulas gerais estão os conceitos jurídicos indeterminados, atuando também enquanto ferramentas de flexibilidade e fluidez interpretativa. "Uma das técnicas utilizadas para dar conta da dinâmica social, e propiciar respostas em conformidade com a Constituição, foi a utilização de textos de elevada vagueza e indeterminação conceitual, ou seja, de conceitos indeterminados e cláusulas gerais" (MÜLLER, 2017, p. 95). Acontece que eles não se confundem: "Há diferença funcional entre as normas compreendidas em cláusulas gerais e as que caracterizam conceitos jurídicos indeterminados, porque, nas primeiras, as consequências (estatuição) só são formadas à vista do caso concreto, enquanto, nas segundas, estas já estão estabelecidas de modo geral e abstrato" (MARTINS-COSTA, 2018, p. 171).
} 
conectando-os, num movimento dialético, com outras soluções sistemáticas (ressistematização).

As cláusulas gerais são espécie de texto normativo cujo antecedente é vago e o consequente é indeterminado. "Há, portanto, uma indeterminação legislativa em ambos os extremos da estrutura lógica normativa" (DIDIER JR., 2010, p. 123), em sua hipótese fática e em seu efeito jurídico. A vagueza e indeterminação são características inerentes a esse instituto. Assim, os textos que integram as cláusulas gerais são construídos a partir da utilização intencional de "termos gerais, vagos, fluidos, o que resulta em larga medida de incerteza do conteúdo e extensão do preceito normativo" (MACÊDO, 2013, p. 02).

As cláusulas gerais, assim, são formadas por textos que sugerem diretrizes para o intérprete, contemplando valores reconhecidos pelo sistema, mas que demandam a construção de soluções em cada caso concreto, uma vez que a lei não as prevê inteiramente (MÜLLER, 2017, p. 95). Ademais, por possuir essas características, a utilização dessa técnica permite capturar uma ampla variedade de casos cujos contornos específicos serão formados jurisprudencialmente, e não necessariamente por meio legislativo (MACÊDO, 2013, p. 03).

Como é de se imaginar, inexiste sistema jurídico que se estruture unicamente por meio de cláusulas gerais ou de regras casuísticas ${ }^{17}$; a harmonia entre esses dois métodos, pois, é essencial para permitir a oxigenação do sistema, impedindo a existência de excessiva vagueza normativa ou de rigidez conceitual em demasia, ambos males indesejáveis ${ }^{18}$.

É necessário reconhecer que as cláusulas gerais não são instituto novo no ordenamento jurídico brasileiro. O direito civil, há bastante tempo, utiliza-se dessa técnica legislativa, sobretudo no âmbito do direito contratual ${ }^{19}$. O Código Civil de 2002 é um importante marco para o tema. Não é exagero dizer que “a mudança paradigmática presente no [...] Código Civil

17 Afinal, “[...] o Direito não pode se dar ao luxo de não ser positivo e o Direito positivo não pode se dar ao luxo de desvalorizar a segurança jurídica. Por definição, um Ordenamento Jurídico deve oferecer segurança e almejar segurança. O Direito não serve para inquietar, mas para direcionar condutas e assegurar expectativas legítimas dos que vivem em sociedade. Deve acalmar, e não sobressaltar" (MARTINS-COSTA, 2015, p. 77).

${ }^{18}$ No mesmo sentido, Fredie Didier Jr. (2010, p. 119, grifo do autor): "Não há sistema jurídico exclusivamente estruturado em cláusulas gerais (que causariam uma sensação perene de insegurança) ou em regras casuísticas (que tornariam o sistema sobremaneira rígido e fechado, nada adequado à complexidade da vida contemporânea). Uma das principais características dos sistemas jurídicos contemporâneos é exatamente a harmonização de enunciados normativos de ambas as espécies".

19 "Os contratos típicos, como compra e venda, locação, mandato, mútuo, prestação de serviços, entre outros, convivem com a possibilidade de celebração de contratos atípicos, conforme permissão do art. 425 do CC" (MÜLLER, 2017, p. 94). 
brasileiro tem nas cláusulas gerais um dos elementos de maior importância em face dos desdobramentos não só teóricos como práticos que acarreta” (LEAL, 2016, p. 07).

As cláusulas gerais, no âmbito civilista, atuam enquanto importantes mecanismos de maleabilidade do direito, voltados ao resgate da materialização jurídica, com especial relevância na esfera contratual, como dito. Sobre o tema, Pastora Leal (2016, p. 07) indica:

Na perspectiva da rematerialização do Direito por meio das cláusulas gerais o
Estado modificaria os contratos para realizar a justiça material. Resulta disso
duas ilações: a) a cláusula geral como mecanismo de intervenção judicial na
economia conformando e configurando a relação contratual; e, b) as cláusulas
gerais permitindo que a decisão judicial, versando sobre os negócios jurídicos,
atenda a valores que não são estritamente econômicos, mas éticos, garantidores
de uma justiça material.

O Código Civil atual, ao contrário de seu antecessor, não está pautado em noções sobejamente concentradas no individualismo e liberalismo, fincando-se nos princípios da socialidade, eticidade e operabilidade, possuindo, segundo acreditam Rafael Bizelli e Gustavo Boyadijan, como principal característica a técnica legislativa das cláusulas gerais. "É um Código flexível, aberto, dinâmico, apto a ser atualizado a cada nova interpretação" (BIZELLI; BOYADJIAN, 2014, p. 04). Essa mudança de metodologia está relacionada ao filtro constitucional atribuído ao direito civil, assim como aos demais ramos do direito, desde a instalação da nova ordem constitucional em 1988, consoante exposto anteriormente.

Dentre as cláusulas gerais de maior proeminência no direito civil estão as cláusulas da boa-fé (art. 113, CC), função social do contrato (art. 421, CC), função social da propriedade (art. $5^{\circ}$, inciso XXIII e art. 170, CRFB; art. 2.035, CC) e vedação ao abuso do direito (art. 187, CC $)^{20}$. Essas diretrizes normativas são orientadas pelo compromisso de superar o individualismo patrimonialista, em razão do reconhecimento de que o direito deve servir ao desenvolvimento da pessoa, inclusive na órbita privada ${ }^{21}$. São previsões que resultam da ingerência do Estado nas relações privadas, preservando o indivíduo em sua qualidade de ser e, consequentemente, em sua dignidade (RACY, 2011, p. 02).

${ }^{20}$ Sem possuir o intento de adentrar à análise minuciosa de cada uma delas, o trabalho se reserva ao objetivo de apontar a existência de tais normas e de verificar a ampla contribuição do âmbito civilista para a modificação da metodologia jurídica contemporânea, hábil a recepcionar maiores diretrizes de textura abertura para imprimir dinamicidade e adaptabilidade ao sistema jurídico.

21 "Há neste momento uma transição de foco, do ter para o ser e o ser pressupõe uma série de situações que não podem ser taxadas, porque se baseiam em um valor e um valor existencial não tem como ser medido, mas apenas compreendido, sendo flexível sua aceitação às inúmeras hipóteses" (RACY, 2011, p. 03). 
Em relação ao fenômeno processual, é importante registrar que o processo é, eminentemente, um produto cultural. Isso ocorre dado ao caráter cultural do próprio direito, cujo estudo e estruturação observam as necessidades sociais, políticas e econômicas de cada momento histórico (MACEDO; MACEDO, 2012, p. 02). Não há como descrever com profundidade a história da ciência processual e seus institutos sem abordá-los a partir da ótica da cultura de determinada sociedade, das ideias e pensamentos dominantes em cada período, e das interferências dessas questões no regramento social e jurídico vigente ${ }^{22}$.

Nessa linha, o processo não pode ser compreendido como um compartimento que se encerra em si; isolado dos fenômenos à sua volta, resumido a mera técnica ${ }^{23}$. Ele é tributário das relações políticas, econômicas e sociais que permeiam a sociedade, e deve estar em consonância com o seu tempo ou, ainda, atuar como um vetor de mudança da realidade atual - situação que, não raramente, é o responsável por apontar os ares das mudanças.

Assim, a cultura é um campo que recorda, a todo o momento, o direito ${ }^{24}$ e o processo, da necessidade de examinar novas formas de transmissão e discussão do conhecimento, assim como da exigência do aperfeiçoamento das vigas estruturantes do sistema jurídico.

O processo - e aqui se confere ênfase ao processo civil, objeto de análise desse trabalho - não se resume ao direito codificado. Não se pode estabelecer uma identificação exata e necessária entre o direito positivo e a justiça (CAPPELLETTI, 1991, p. 01). É o que também compreende Piero Calamandrei:

Aparentemente, todo o direito processual está contido nos códigos e, sobre a base do direito codificado, a doutrina levanta construções monumentais de conceitos, majestosos com como catedrais góticas. No entanto, em realidade, o processo não é isso; não é somente isso. [...] o processo, tal como está escrito no Código, não passa de um modelo vazio que, ao se traduzir em realidade, assume diferentes formas, segundo as diversas substâncias que colocam em seu interior (2018, p. 29).

22 Do mesmo modo ressalta Carlos Alberto Alvaro de Oliveira: "Qualquer reflexão moderna sobre o processo há de levar em conta suas conexões internas e externas. Não basta tão somente o estudo da técnica, simples meio para atingir-se determinado resultado, porquanto o processo como fenômeno cultural se conforma em razão dos valores imperantes em determinada sociedade, das suas idéias, utopias, estratégias de poder, fatores sociais, econômicos e políticos" (2001, p. 50).

${ }^{23}$ Assim como não há como o processo se resumir à técnica, igualmente pernicioso é o desprezo ao elemento técnico. "Nenhum processualista que preze a sua ciência tem o direito de desinteressar-se pura e simplesmente das questões técnicas" (BARBOSA MOREIRA, 1997, p. 27).

${ }^{24}$ Como afirma Judith Martins-Costa (2004, p. 04): "A cultura é, em suma, o a priori - absolutamente não-estático - que define a nossa forma de ser, de conhecer, de compreender, de sentir e de regular as nossas relações, inclusive juridicamente". 
Embora a norma codificada ocupe posição de destaque na tradição jurídica brasileira, e, assim, na tradição jurídica processual, ela não esgota os elementos necessários à compreensão do fenômeno processual. O formalismo e o dogmatismo jurídico não representam fielmente a realidade, extremamente mais complexa (CAPPELLETTI, 1991, p. 02). Então, é inevitável reconhecer que "o direito processual, fonte que era - conforme visão fartamente disseminada de formalismo dogmatista, não tardou a fazer parte do quadro de objetos sujeitos ao trabalho de reconstrução e ressignificação" (SILVA, 2018, p. 04).

A lei não aprisiona ou contempla, integralmente, o sentido do processo, sua finalidade e, sobretudo, o impacto social oriundo de sua aplicação, uma vez que "as leis processuais não são outra coisa que uma frágil rede, em cujas malhas pressiona e, às vezes, desborda a realidade social" (CALAMANDREI, 2018, p. 32). Não obstante, do mesmo modo que a legislação não pode ser vista como um fator de contingência absoluta da ciência processual, seu estudo também não pode ser desprezado; o aspecto normativo do direito, pois, não pode ser renegado, como Mauro Cappelletti (1991, p. 02) reconhece.

O reconhecimento do caráter cultural do processo não se direciona a reduzir a importância da norma legislada, mas atua para compatibilizá-la com os valores e ideais vivenciados em cada circunscrição política. Recorda-se lição de Dalmo de Abreu Dallari direcionada não apenas ao direito processual, mas à ciência jurídica:

[...] quem procede ao estudo jurídico de um fato ou de uma situação
determinada, seja para a elaboração de uma lei, para imposição de uma
exigência legal, para decisão de um conflito de direitos, seja para qualquer outro
objetivo jurídico, deve considerar também os aspectos não jurídicos que possam
ter relevância para o Direito (2013, p. 18-19).

Precisamente, nesse cenário se inserem as cláusulas gerais processuais. A adoção desse instrumento de maneira proeminente pela ordem processual civil representa a intensa relação estabelecida entre o processo e o direito privado - e entre os últimos e as diretrizes constitucionais -, com o objetivo de situar o ambiente processual no campo de reconhecimento dos valores compreendidos como relevantes pela ordem jurídica.

Segundo observa Fredie Didier Jr., as cláusulas gerais, antes restritas ao ambiente privatista, passaram a compor o processo, isto é, notadamente invadiram o direito processual (2010, p. 123), uma vez que também necessita de maior flexibilidade para atender às exigências do caso concreto. 
O devido processo legal, diretriz normativa de matiz constitucional (art. $5^{\circ}$, LIV, CRFB), é o mais importante e significativo exemplo de cláusula geral processual (DIDIER JR., 2010 , p. 123$)^{25}$. Lucas Buril acentua que a natureza ampla do devido processo legal permite a adequação procedimental e contraria a ideia de incidência universal e estanque às situações jurídicas (MACÊDO, 2013, p. 09), uma vez que o seu adequado alcance depende substancialmente das nuances identificadas no exame minucioso do caso. A sua indeterminação a priori contribui para a sua máxima aplicabilidade.

Analisando o tema ainda sob a vigência do diploma processual revogado, Fredie Didier Jr. (2010, p. 123) indica que já era possível identificar diversas cláusulas gerais processuais, como a cláusula geral executiva (art. 461, § 5, CPC/73); o poder geral de cautela (art. 798, CPC/73); a cláusula geral do abuso do direito do exequente (art. 620 do CPC/73); a cláusula geral da boa-fé processual (art. 14, II, CPC/73); cláusula geral de publicidade do edital de hasta pública (art. 687, § 2º, $\mathrm{CPC} / 73$ ); cláusula geral de adequação do processo e da decisão em jurisdição voluntária (art. 1.109, CPC/73), dentre outras.

Desse cenário é possível extrair a constatação de que o Código de Processo Civil atual não inaugurou o tema das cláusulas gerais no processo civil brasileiro: ainda sob o regramento passado anterior já era possível identificar a previsão dessa técnica. Na realidade, o mérito que pode ser atribuído ao legislador reformista é o de ter expandido o emprego desse importante instrumento, mantendo e ampliando as hipóteses existentes.

Três das mais significativas inserções realizadas pelo diploma processual civil em vigor são as cláusulas gerais de eficiência (art. 8, CPC), de atipicidade negocial (art. 190 e 200, CPC) e de atipicidade executiva (art. 139, inciso IV, CPC).

Eduardo Luiz Cavalcanti Campos enuncia que o art. $8^{\circ}$ do $\mathrm{CPC}$, ao atribuir ao juiz o dever de agir com eficiência na aplicação do ordenamento jurídico, adota uma cláusula geral processual de eficiência, "pois o enunciado normativo não estabelece os efeitos da norma jurídica enunciada, de modo que a identificação desses efeitos é tarefa que caberá ao aplicador da norma diante da situação concreta" (2018, p. 104).

Nesse caso, as imprecisões conceituais pairam sobre dois elementos nucleares, quais sejam, aplicação do ordenamento jurídico e agir com eficiência. Com essa previsão, a eficiência,

\footnotetext{
${ }^{25}$ Inclusive, "a cláusula geral do devido processo, como se percebe, é dotada de grande vagueza, o que certamente permitiu sua utilização por tanto tempo, sempre com o aspecto garantista e de vanguarda que possui, vindo a ser incorporado no Direito brasileiro na Constituição Federal de 1988" (MACÊDO, 2013, p. 03).
} 
diretriz normativa que apresenta natureza constitucional explícita (art. 37, caput, CRFB), classicamente analisada como um dever assumido pela Administração Pública no exercício de atividade puramente administrativa, passa a integrar a preocupação do judiciário em sua atividade finalista - a prestação adequada da tutela jurisdicional.

De outra banda, Marcelo Abelha Rodrigues, ao analisar o atual regime de tutela executiva, aduz que, em um universo de dispositivos engessados e extraídos praticamente por meio da repetição das normas contidas no Código de 1973 e 1939, “o artigo 139, IV apresenta-se como um oásis de esperança para uma ехесиção mais rente com a promessa constitucional de tutela dos direitos" (2018, p. 33). Por essa razão, o autor acredita que, ao lado de outras normas fundamentais do Código e das demais cláusulas gerais nele existentes, é possível repensar a tutela jurisdicional executiva sem a imobilidade burocrática característica de outrora (2018, p. 33).

Para Fredie Didier Jr., o caput do art. 190 é uma cláusula geral da qual se extrai o subprincípio da atipicidade da negociação processual, sendo um subprincípio porque atua em prol da concretização do princípio do respeito ao autorregramento da vontade no processo (2018, p. 29).

Nesse momento, cabe destacar que, embora a existência dos negócios processuais na experiência brasileira remeta ao período das ordenações (NOGUEIRA, 2018, p. 262), tendo sido figura permanente nas legislações processuais brasileiras posteriores, não se tem como desprezar que o art. 190 do Código representa uma acentuada novidade no direito nacional.

O legislador optou, de maneira inequívoca e sem precedentes na ordem jurídica brasileira, em permitir a celebração de negócios jurídicos processuais de modo amplo, estando no campo de liberdade e vontade das partes, obedecidos certos parâmetros, o preenchimento do conteúdo da denominada cláusula geral de negociação processual (CUNHA, 2017, p. 68), cláusula geral de negociação sobre o processo (DIDIER JR., 2019, p. 447 e NOGUEIRA, 2018, p. 262) ou cláusula geral de atipicidade negocial (BARREIROS, 2017, p. 180).

Ela está presente no art. 190 do Código, o qual estipula que: "Versando o processo sobre direitos que admitam autocomposição, é lícito às partes plenamente capazes estipular mudanças no procedimento para ajustá-lo às especificidades da causa e convencionar sobre os seus ônus, poderes, faculdades e deveres processuais, antes ou durante o processo".

Trata-se, como se vê, de importante autorizativo para a construção customizada do procedimento e das posições jurídicas titularizadas pelas partes no processo. É certo que os 
negócios processuais já estavam previstos na legislação processual revogada, contudo, "nunca se teve tamanho espaço de participação dos litigantes no desenrolar da atividade jurisdicional, a ponto de possibilitar que as partes construam, negocialmente, o próprio procedimento" (NOGUEIRA, 2018, p. 263).

Nota-se, então, que a adoção de uma cláusula geral de negociação processual fortaleceu o instituto dos negócios processuais na ordem jurídica brasileira e inaugurou um novo momento no estudo do tema, prestigiando o exercício da liberdade no processo, de modo a observar o modelo cooperativo e permitir maior elasticidade procedimental.

Em suma, as cláusulas gerais processuais informam o processo civil brasileiro de modo a atribuir ao julgador a função de buscar concretude aos seus comandos, retirando, assim, a carga fluida de suas definições e consequências jurídicas a partir da utilização do método de concreção, subsidiado pelos elementos fornecidos pelo caso em análise.

Merece relevo o registro de que muitas cláusulas gerais processuais inseridas no Código de Processo Civil vigente integram as normas fundamentais do processo, o que detona a sua posição jurídica de destaque no plano processual, assim como o seu importante papel na busca de uma justiça civil desenvolvida de modo efetivo e rente às necessidades dos jurisdicionado detidamente identificadas na pretensão jurídica discutida.

\section{CONCLUSÃO}

A transformação da metodologia jurídica do século XX impactou o modo de compreensão do direito, modificando a relação do Estado com a sociedade, assim como sendo responsável por modificar as vigas estruturantes do pensamento e da dogmática jurídica. Nesse âmbito, o direito privado foi reformulado, migrando de uma ótica individual-patrimonialista para uma visão preocupada com o desenvolvimento humano, com ênfase na dignidade humana e nos valores caros à sociedade. Um dos principais reflexos disso foi a instituição da técnica legislativa das cláusulas gerais.

Como exposto, as cláusulas gerais se apresentam como normas integrantes de um modelo jurídico aberto, dotadas de vagueza e imprecisão em sua conceituação e efeitos jurídicos. A sua incidência normativa fornece condições do sistema jurídico operar de modo flexível, aberto e dinâmico, possibilitando o enfrentamento a questões complexas e fluidas, oriundas das diversas relações sociais. 
Nessa ótica, o trabalho buscou apontar que essa técnica legislativa toca a outros campos do direito, em especial o direito processual civil, passando-se a reconhecer a existência de verdadeiras cláusulas gerais processuais, oriundas dos reflexos da transformação metodológica civilista-constitucional. Expôs-se a compreensão de que as cláusulas gerais não são fenômeno restrito ao direito privado; revelam-se, em verdade, enquanto técnica legislativa que passa a conviver com os demais instrumentos de concreção do direito, possuindo ampla importância no processo civil brasileiro e, em especial, vasta previsão no Código de Processo Civil em vigor.

\section{REFERÊNCIAS}

ABBOUD, Georges; CARNIO, Henrique Garbellini; OLIVEIRA, Rafael Tomaz de. Introdução à Teoria e à Filosofia do Direito. 3. ed. São Paulo: Revista dos Tribunais, 2015.

ASCENSÃO, José de Oliveira. Concorrência de Fontes, "Diálogo das Fontes" e Unidade da Ordem Jurídica. In: SILVA NETO, Francisco Antônio de Barros e Silva; et. al (coord.). Relações e Influências Recíprocas entre Direito Material e Direito Processual, $6^{\mathrm{a}}$ série. Salvador: Juspodivm, 2017.

BARBOSA MOREIRA, José Carlos. Efetividade do processo e técnica processual. Revista de Processo, vol. 77, jan.-mar., 1995.

BARREIROS, Lorena Miranda Santos. Convenções processuais e poder público. Salvador: Juspodivm, 2017.

BIZELLI, Rafael Ferreira; BOYADJIAN, Gustavo Henrique Velasco. A cláusula geral da função social dos contratos. Revista de Direito Privado, vol. 58, abr.-jun., 2014.

CABRAL, Antonio do Passo. Convenções processuais. 2. ed. Salvador: Juspodivm, 2018.

CALAMANDREI, Piero. Processo e Democracia: conferências realizadas na Faculdade de Direito da Universidade Nacional Autônoma do México. Tradução: Mauro Fonseca Andrade. 2. ed. Porto Alegre: Livraria do Advogado, 2018.

CAMPOS, Eduardo Luiz Cavalcanti. O princípio da eficiência no processo civil brasileiro. Rio de Janeiro: Forense, 2018.

CAPPELLETTI, Mauro. O acesso à justiça e a função do jurista em nossa época. Revista de Processo, vol. 61, jan-mar, 1991.

COSTA FILHO, Venceslau Tavares. Tendências do direito civil nos países de tradição romanogermânica: transnacionalização e recodificação. Uma análise a partir da reforma do direito obrigacional alemão. In: SILVA NETO, Francisco Antônio de Barros e Silva; et. al (coord.). Relações e Influências Recíprocas entre Direito Material e Direito Processual, $6^{\mathrm{a}}$ série. Salvador: Juspodivm, 2017. 
CUNHA, Leonardo Carneiro da. Normas fundamentais no novo CPC brasileiro. In: CAPELO, Maria José; et al (org). Processo Civil Comparado: análise entre Brasil e Portugal. São Paulo: Forense, 2017.

DALLARI, Dalmo de Abreu. A Constituição na vida dos povos: da idade média ao século XXI. 2. ed. São Paulo: Saraiva, 2013.

DIDIER JR., Fredie. Cláusulas Gerais Processuais. Revista Opinião Jurídica, n. 12, 2010.

DIDIER JR., Fredie. Curso de direito processual civil: introdução ao direito processual civil, parte geral e processo de conhecimento. 19. ed. Salvador: Juspodivm, 2017.

DIDIER JR., Fredie. Curso de direito processual civil: Introdução ao Direito Processual Civil, Parte Geral e Processo de Conhecimento. 21. ed. Salvador: Juspodivm, 2019.

DIDIER JR., Fredie. Negócios jurídicos processuais atípicos no CPC-2015. In: DIDIER JR, Fredie. Ensaios sobre os negócios jurídicos processuais. Salvador: Juspodivm, 2018.

DINAMARCO, Cândido Rangel; LOPES, Bruno Vasconcelos Carrilho. Teoria geral do novo processo civil. 2. ed. São Paulo: Malheiros, 2017.

JORGE JUNIOR, Alberto Gosson. Cláusulas gerais no novo Código Civil. São Paulo: Saraiva, 2004.

LEAL, Pastora do Socorro Teixeira. "Diálogo das Fontes" e Coerência na Concretização de Direitos Fundamentais. In: Ciência e interpretação do direito: homenagem a Daniel Coelho de Souza. 1. ed. Rio de Janeiro: Lumen Juris, 2016.

MACEDO, Elaine Harzheim; MACEDO, Fernanda dos Santos. O direito processual civil e a pós-modernidade. Revista de Processo, vol. 204, fev., 2012.

MACÊDO, Lucas Buril de. A concretização direta de cláusula geral no devido processo legal processual no Supremo Tribunal e no Superior Tribunal de Justiça. Revista de Processo, vol. 216, fev., 2013.

MARTINS-COSTA, Judith. A boa-fé no direito privado: critérios para a sua aplicação. 2. ed. São Paulo: Saraiva, 2018.

MARTINS-COSTA, Judith. Como harmonizar os modelos jurídicos abertos com a segurança jurídica dos contratos? (Notas para uma Palestra). Revista Brasileira de Direito Civil, vol. 5, jul.set., 2015.

MARTINS-COSTA, Judith. Culturalismo e experiência no novo código civil. Revista dos Tribunais, vol. 819, jan., 2004. 
MORAES, Maria Celina Bodin de. Danos à pessoa humana: uma leitura civil-constitucional dos danos morais. In: SARLET, Ingo Wolfgang (org.). Constituição, direitos fundamentais e direito privado. 2. ed. Porto Alegre: Livraria do Advogado, 2006.

MÜLLER, Julio Guilherme. Negócios processuais e desjudicialização da produção da prova: análise econômica e jurídica. São Paulo: Revista dos Tribunais, 2017.

NOGUEIRA, Pedro Henrique. Negócios jurídicos processuais. 3. ed. Salvador: Juspodivm, 2018.

OLIVEIRA, Carlos Alberto Alvaro de. Efetividade e processo de conhecimento. Revista de Processo, vol. 96, out.-dez., 1999.

OLIVEIRA, Carlos Alberto Alvaro de. Mauro Cappelletti e o Direito Processual Brasileiro. Revista da Faculdade de Direito da UFRGS, v. 20, out., 2001.

RACY, Vivien. Efetivação da dignidade da pessoa humana e as cláusulas gerais. Revista de Direito Privado, vol. 47, jul.-set., 2011.

RAMOS, Carmem Lucia Silveira. A constitucionalização do direito privado e a sociedade sem fronteiras. In: Repensando Fundamentos do Direito Civil Brasileiro Contemporâneo. Rio de Janeiro: Renovar, 1998.

RODRIGUES, Marcelo Abelha. Fundamentos da tutela executiva. Gazeta Jurídica, 2018.

SARMENTO, Daniel. Direitos fundamentais e relações privadas. Rio de Janeiro: Lumen Juris, 2004.

SILVA, Adelvan Oliverio. A importância e a possibilidade dos conceitos de prova e verdade na análise do direito fundamental de ação: um ensaio de compreensão das condições da ação a partir de uma teoria geral do processo. In: OLIVERIO, Adelvan; HOMCI, Arthur Laércio; MENDES NETO, João Paulo (coord.). Direito Processual: inovações e perspectivas. Rio de Janeiro: Lumen Juris, 2018.

TEDESCHI, Sebastián Ernesto. El Waterloo del Código Civil Napoleónico: una mirada crítica a los fundamentos del derecho privado moderno para la construcción de sus nuevos principios generales. In: COURTIS, Christian (comp.). Desde otra mirada: textos de teoría crítica del derech. Buenos Aires: Eudeba, 2001.

UBILLOS, Juan María Bilbao. ¿En qué medida vinculan a los particulares los derechos fundamentales? In: SARLET, Ingo Wolfgang (org.). Constituição, direitos fundamentais $e$ direito privado. 2. ed. Porto Alegre: Livraria do Advogado, 2006. 